\title{
Multimodality evoked potentials in HTLV-I associated myelopathy
}

\author{
RYUSUKE KAKIGI, HIROSHI SHIBASAKI, YASUO KURODA, CHIYOKO ENDO, \\ KEN-ICHIRO ODA, AKIO IKEDA, KAZUHITO HASHIMOTO*
}

From the Departments of Internal Medicine and Surgery, ${ }^{*}$ Saga Medical School, Nabeshima, Saga City, Japan

SUMMARY Multimodality evoked potentials (EPs) consisting of somatosensory EPs (SEPs), visual EPs (VEPs) and brainstem auditory EPs (BAEPs) were studied in 16 cases with HTLV-I associated myelopathy (HAM). Median nerve SEPs were normal in all cases. In posterior tibial nerve SEPs, the potential recorded at the 12 th thoracic spinal process was normal in every case, but cortical components were significantly prolonged in 10 cases, although five of these showed no sensory impairment. BAEPs were normal in every case whose hearing was intact, but VEPs were abnormal in two cases whose visual acuities were normal. The present results in HAM indicate predominant lesion in the thoracic cord, and might also suggest some subclinical lesion in the visual pathway.

Myelopathy associated with high antibody titre against the human T-lymphotropic virus type-I (HTLV-I) has recently aroused much interest. Since Osame et al's first recognition of this clinical entity in Kagoshima, ${ }^{1}$ approximately 300 cases of HTLV-I associated myelopathy (HAM) have been reported in Japan. $^{2}$

It is well known that multimodality EPs including somatosensory EPs (SEPs), visual EPs (VEPs) and brainstem auditory EPs (BAEPs) can detect abnormalities more often than a single modality EP in various neurological diseases, in particular multiple sclerosis. ${ }^{3}$ We report the study of multimodality EPs in the detection of abnormalities, particularly subclinical changes, in HAM.

\section{Patients and Methods}

Diagnostic criteria of HAM proposed by Osame et al ${ }^{124}$ were adopted. The criteria are the following: (1) chronic progressive myelopathy of adult onset, (2) high antibody titres to HTLV-I in serum and cerebrospinal fluid, (3) predominantly symmetrical upper motor neuron disorder, with

Address for reprint requests: Ryusuke Kakigi, M.D., Department of Internal Medicine, Saga Medical School, Nabeshima, Saga City, 840-01, Japan.

Received 1 March 1988

Accepted 2 April 1988 mild sensory and bladder dysfunctions, and (4) presence of adult T-cell leukaemia-like cells in the peripheral blood.

Sixteen cases, 10 women and six men, who were diagnosed as HAM based on the above criteria, were studied. The age of the patients ranged from 32 to 69 years with the mean of 52. Motor and sensory function of the upper limbs were normal in all cases. In the lower extremities, symmetrical and markedly hyperactive deep tendon reflexes (DTRs) and mild to moderate weakness were present in all cases. Superficial and joint sensation were normal in all cases, but vibratory sensation was impaired to some degree in six cases.

Short-latency SEPs following stimulation of the median nerve at the wrist as well as the posterior tibial nerve at the ankle, VEPs following black-and-white checkerboard pattern reversal stimulation, and BAEPs following click sound stimulation were recorded using routine methods following the guidelines of the American EEG society. ${ }^{5}$ The bandpass of the amplifier was $30-3000 \mathrm{~Hz}, 1-500 \mathrm{~Hz}$ and $30-3000 \mathrm{~Hz}$ for SEPs, VEPs and BAEPs, respectively. The nomenclature of each recognisable component also followed the guidelines. ${ }^{5}$ The upper limit of the normal range of peak latencies as well as interpeak latencies was set to mean +3 standard deviations of normal values in our laboratory.

\section{Results}

The occurrence of abnormalities in each EP are summarised in the table.

(1) SEPs: Peripheral, cervical and cortical median nerve SEPs were normal in every case. The posterior 


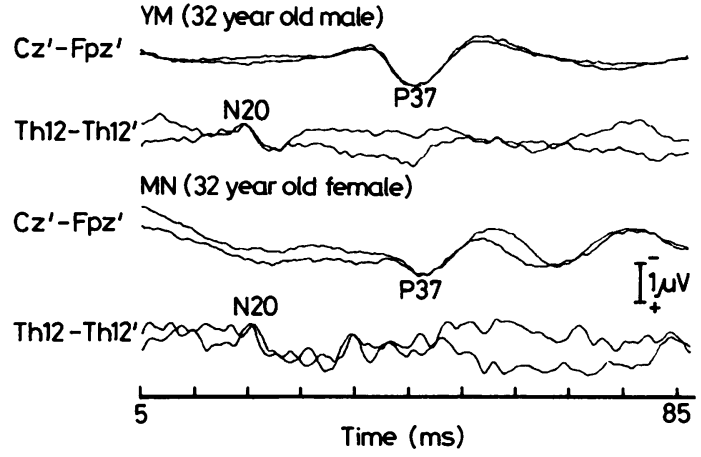

Fig SEPs following stimulation of the left posterior tibial nerve at ankle in two cases with HAM. Peak latency of N2O was normal in both cases, but interpeak latency, N20-P37, was significantly prolonged, $25.6 \mathrm{~ms}$ in case 1 and $25.8 \mathrm{~ms}$ in case 2. These two cases had no sensory symptom in the lower extremities. $C z^{\prime}$; foot sensory area or $2 \mathrm{~cm}$ behind $C z$ (international 10-20 system), Fpz'; midway between positions Fpz and Fz of the 10-20 system, Th12 and Th12'; the 12th thoracic spinous process and the point $4 \mathrm{~cm}$ rostral to Th12. 400 sweeps were averaged in each case.

tibial nerve SEPs, the potential recorded at the 12th thoracic spinal process, N20, was normal in every case. The initial cortical component, P37, was clearly identified in every case, but it was prolonged in 10 cases (the upper limit of normal range was $38.7 \mathrm{~ms}$ ), ${ }^{6}$ the longest latency being $51.6 \mathrm{~ms}$ without significant left-right difference (fig). The interpeak latency, N20-P37, was also prolonged in those 10 cases (the upper limit was $21.7 \mathrm{~ms}),{ }^{6}$ the longest being $32.6 \mathrm{~ms}$. The prolonged N20-P37 correlated neither with the sensory impairment of any modality nor with the upper motor neuron signs. Among those 10 cases with significantly prolonged N20-P37, five cases had no sensory impairment in the lower extremities (fig).

(2) VEPs: VEP studies were not done in one case with severe congenital visual disturbance. The major positive peak, P100, was of normal waveform and latency (the upper limit was $112.4 \mathrm{~ms}$ ) in 13 out of 15 cases. In the other two cases whose visual acuities were normal, P100 was significantly prolonged to the full-field $\left(16^{\circ}\right)$

Table Occurrence of abnormal EPs in 16 cases with HAM. (No. of abnormal cases/no. of cases tested)

\begin{tabular}{lr}
\hline Median nerve SEPs & $0 / 16$ cases \\
Posterior tibial nerve SEPs & $10 / 16$ cases \\
VEPs & $2 / 15$ cases \\
BAEPs & $5 / 16$ cases* \\
Posterior tibial nerve SEPs and/or VEPs & $11 / 16$ cases \\
\hline
\end{tabular}

No case showed significant left-right difference in SEPs and VEPs * Deafness or marked hearing disturbance was present in all five cases whose BAEPs were abnormal.
(130 ms and $134 \mathrm{~ms}$, respectively), half-field $\left(16^{\circ}\right)$ and central-field $\left(5^{\circ}\right)$ stimulation with a small left-right difference.

(3) BAEPs: Deafness or marked hearing disturbance was present in seven ears of five cases. The diagnosis of the mixed-type hearing trouble was made for them by neuro-otological studies, and no consistent BAEP component could be identified following stimulation of those troubled ears. Waves I to V, and interpeak latencies, I-V as well as III-V, were normal following stimulation of the other ears.

\section{Discussion}

Abnormal posterior tibial nerve SEPs with normal median nerve SEPs identified in the present cases indicate lumbar or thoracic spinal cord lesions or distal axonal degeneration of the gracile fascicle. SEPs are considered to be generated by the stimulus signals ascending through the posterior column. The fact that SEPs were abnormal in five cases whose deep sensations were intact suggested the capability of SEPs to detect subclinical posterior column lesions in HAM.

In the VEPs, P100 was significantly prolonged in two cases whose visual acuities were normal. This result is similar to VEP abnormalities in multiple sclerosis, ${ }^{37}$ although the incidence of clinical optic nerve impairment as well as of subclinical VEP abnormalities in multiple sclerosis ${ }^{3} 7$ is much higher than in the present HAM cases.

Unlike SEPs or VEPs, BAEPs were normal in every case whose hearing was normal.

The results in HAM indicate that the predominant lesions are in the thoracic cord, and might also suggest some subclinical lesion in the visual pathway, although these are rare. The conclusions are compatible with the previous reports concerning EPs in HAM ${ }^{8-10}$

Recently, there have been reports ${ }^{1-13}$ that many cases of tropical spastic paraparesis (TSP) have a high antibody titre against HTLV-I. As the clinical findings in this disorder are very similar to those in HAM, the two clinical entities are probably caused by the same mechanisms. ${ }^{4}$ However, SEPs, VEPs and BAEPs were abnormal in 60, 67 and $64 \%$ of TSP cases, respectively. ${ }^{13}$ The abnormality rate of VEPs and BAEPs in TSP appeared to be much higher than that in the present study as well as that in the other reports of HAM, ${ }^{10}$ but it is still uncertain what caused this significant difference between TSP and HAM.

This study was supported by Grant No. 85-17 of the Research Committee of Myelopathy, from the National Centre for Nervous, Mental and Muscular Disorders (NCNMMD) of the Ministry of Health and Welfare, Japan. 


\section{References}

1 Osame M, Usuku K, Izumo S, et al. HTLV-I associated myelopathy, a new clinical entity. Lancet 1986;i:1031-2.

2 Osame M, Igata A, Matsumoto M, Usuku K, Kitajima I, Takahashi $\mathbf{K}$. On the discovery of a new clinical entity: Human T-cell lymphotropic virus type Iassociated myelopathy (HAM). Shinkei Kenkyu no Shinpo 1987;31:727-45.

3 Chiappa KC. Pattern shift visual, brainstem auditory, and short-latency somatosensory evoked potentials in multiple sclerosis. Neurology 1980;30:110-23.

4 Osame M, Matsumoto M, Usuku K, et al. Chronic progressive myelopathy associated with elevated antibodies to human T-lymphotropic virus type I and adult T-cell leukemialike cells. Ann Neurol 1987;21:117-21.

5 American Electroencephalographic Society. Recommended standards for visual system, short-latency auditory and short-latency somatosensory evoked potentials. J Clin Neurophysiol 1984;1:15-53.

6 Kakigi R. The effect of aging on somatosensory evoked potentials following stimulation of the posterior tibial nerve in man. Electroencephalogr Clin Neurophysiol 1987;68:277-86.
7 Halliday AM. The visual evoked potential in the investigation of diseases of the optic nerve. In: Halliday AM, ed. Evoked Potentials in Clinical Testing. Edinburgh: Churchill Livingstone, 1982:187-234.

8 Arimura $\mathbf{K}$, Rosales LR, Osame M, Igata A. Clinical electrophysiologic studies of HTLV-I-associated myelopathy. Arch Neurol 1987;44:609-12.

9 Arimura Y, Arimura K, Osame M, Igata A. Neuroophthalmological abnormalities in HTLV-I associated myelopathy. Neuro-ophthalmology 1987;7:243-8.

10 Arimura K, Arimura Y, Osame M, Rosales RL. HTLVI-associated myelopathy (HAM): Clinical neurophysiologic studies. Shinkei Kenkyu no Shinpo 1987;31:961-7.

11 Gessain A, Vernant JC, Maurs L, et al. Antibodies to human T-lymphotropic virus type-I in patients with tropical spastic paraparesis. Lancet 1985;ii:407-9.

12 Vernant JC, Maurs L, Gessain A, et al. Endemic tropical spastic paraparesis associated with human $T$ lymphotropic virus type I: a clinical and seroepidemiological study of 25 cases. Ann Neurol 1987;21:123-30.

13 Newton M, Miller D, Rudge P, et al. Antibody to human T-lymphotropic virus type 1 in West-Indian-born UK residents with spastic paraparesis. Lancet 1987;i: 415-6. 